\title{
Does playing violent video games cause aggression? A longitudinal intervention study
}

\author{
Simone Kühn ${ }^{1,2} \cdot$ Dimitrij Tycho Kugler $^{2} \cdot$ Katharina Schmalen $^{1} \cdot$ Markus Weichenberger $^{1} \cdot$ Charlotte Witt $^{1}$. \\ Jürgen Gallinat ${ }^{2}$
}

Received: 19 August 2017 / Revised: 3 January 2018 / Accepted: 15 January 2018 / Published online: 13 March 2018

(c) The Author(s) 2018. This article is published with open access

\begin{abstract}
It is a widespread concern that violent video games promote aggression, reduce pro-social behaviour, increase impulsivity and interfere with cognition as well as mood in its players. Previous experimental studies have focussed on short-term effects of violent video gameplay on aggression, yet there are reasons to believe that these effects are mostly the result of priming. In contrast, the present study is the first to investigate the effects of long-term violent video gameplay using a large battery of tests spanning questionnaires, behavioural measures of aggression, sexist attitudes, empathy and interpersonal competencies, impulsivity-related constructs (such as sensation seeking, boredom proneness, risk taking, delay discounting), mental health (depressivity, anxiety) as well as executive control functions, before and after 2 months of gameplay. Our participants played the violent video game Grand Theft Auto V, the non-violent video game The Sims 3 or no game at all for 2 months on a daily basis. No significant changes were observed, neither when comparing the group playing a violent video game to a group playing a non-violent game, nor to a passive control group. Also, no effects were observed between baseline and posttest directly after the intervention, nor between baseline and a follow-up assessment 2 months after the intervention period had ended. The present results thus provide strong evidence against the frequently debated negative effects of playing violent video games in adults and will therefore help to communicate a more realistic scientific perspective on the effects of violent video gaming.
\end{abstract}

The concern that violent video games may promote aggression or reduce empathy in its players is pervasive and given the popularity of these games their psychological impact is an urgent issue for society at large. Contrary to the custom, this topic has also been passionately debated in the scientific literature. One research camp has strongly argued that violent video games increase aggression in its players $[1,2]$, whereas the other camp [3, 4] repeatedly concluded

Electronic supplementary material The online version of this article (https://doi.org/10.1038/s41380-018-0031-7) contains supplementary material, which is available to authorized users.

\section{Simone Kühn}

skuehn@uke.de

1 Max Planck Institute for Human Development, Center for Lifespan Psychology, Lentzeallee 94, 14195 Berlin, Germany

2 Clinic and Policlinic for Psychiatry and Psychotherapy, University Clinic Hamburg-Eppendorf, Martinistraße 52, 20246

Hamburg, Germany that the effects are minimal at best, if not absent. Importantly, it appears that these fundamental inconsistencies cannot be attributed to differences in research methodology since even meta-analyses, with the goal to integrate the results of all prior studies on the topic of aggression caused by video games led to disparate conclusions $[2,3]$. These meta-analyses had a strong focus on children, and one of them [2] reported a marginal age effect suggesting that children might be even more susceptible to violent video game effects.

To unravel this topic of research, we designed a randomised controlled trial on adults to draw causal conclusions on the influence of video games on aggression. At present, almost all experimental studies targeting the effects of violent video games on aggression and/or empathy focussed on the effects of short-term video gameplay. In these studies the duration for which participants were instructed to play the games ranged from $4 \mathrm{~min}$ to maximally $2 \mathrm{~h}$ (mean $=22 \mathrm{~min}$, median $=15 \mathrm{~min}$, when considering all experimental studies reviewed in two of the recent major meta-analyses in the field $[3,5]$ ) and most frequently the 
effects of video gaming have been tested directly after gameplay.

It has been suggested that the effects of studies focussing on consequences of short-term video gameplay (mostly conducted on college student populations) are mainly the result of priming effects, meaning that exposure to violent content increases the accessibility of aggressive thoughts and affect when participants are in the immediate situation [6]. However, above and beyond this the General Aggression Model (GAM, [7]) assumes that repeatedly primed thoughts and feelings influence the perception of ongoing events and therewith elicits aggressive behaviour as a long-term effect. We think that priming effects are interesting and worthwhile exploring, but in contrast to the notion of the GAM our reading of the literature is that priming effects are short-lived (suggested to only last for $<5 \mathrm{~min}$ and may potentially reverse after that time [8]). Priming effects should therefore only play a role in very close temporal proximity to gameplay. Moreover, there are a multitude of studies on college students that have failed to replicate priming effects [9-11] and associated predictions of the so-called GAM such as a desensitisation against violent content [12-14] in adolescents and college students or a decrease of empathy [15] and pro-social behaviour [16, 17] as a result of playing violent video games.

However, in our view the question that society is actually interested in is not: "Are people more aggressive after having played violent video games for a few minutes? And are these people more aggressive minutes after gameplay ended?", but rather "What are the effects of frequent, habitual violent video game playing? And for how long do these effects persist (not in the range of minutes but rather weeks and months)?" For this reason studies are needed in which participants are trained over longer periods of time, tested after a longer delay after acute playing and tested with broader batteries assessing aggression but also other relevant domains such as empathy as well as mood and cognition. Moreover, long-term follow-up assessments are needed to demonstrate long-term effects of frequent violent video gameplay. To fill this gap, we set out to expose adult participants to two different types of video games for a period of 2 months and investigate changes in measures of various constructs of interest at least one day after the last gaming session and test them once more 2 months after the end of the gameplay intervention. In contrast to the GAM, we hypothesised no increases of aggression or decreases in pro-social behaviour even after long-term exposure to a violent video game due to our reasoning that priming effects of violent video games are short-lived and should therefore not influence measures of aggression if they are not measured directly after acute gaming. In the present study, we assessed potential changes in the following domains: behavioural as well as questionnaire measures of aggression, empathy and interpersonal competencies, impulsivity-related constructs (such as sensation seeking, boredom proneness, risk taking, delay discounting), and depressivity and anxiety as well as executive control functions. As the effects on aggression and pro-social behaviour were the core targets of the present study, we implemented multiple tests for these domains. This broad range of domains with its wide coverage and the longitudinal nature of the study design enabled us to draw more general conclusions regarding the causal effects of violent video games.

\section{Materials and methods}

\section{Participants}

Ninety healthy participants (mean age $=28$ years, $\mathrm{SD}=$ 7.3, range: $18-45,48$ females) were recruited by means of flyers and internet advertisements. The sample consisted of college students as well as of participants from the general community. The advertisement mentioned that we were recruiting for a longitudinal study on video gaming, but did not mention that we would offer an intervention or that we were expecting training effects. Participants were randomly assigned to the three groups ruling out self-selection effects. The sample size was based on estimates from a previous study with a similar design [18]. After complete description of the study, the participants' informed written consent was obtained. The local ethics committee of the Charité University Clinic, Germany, approved of the study. We included participants that reported little, preferably no video game usage in the past 6 months (none of the participants ever played the game Grand Theft Auto V (GTA) or Sims 3 in any of its versions before). We excluded participants with psychological or neurological problems. The participants received financial compensation for the testing sessions (200 Euros) and performance-dependent additional payment for two behavioural tasks detailed below, but received no money for the training itself.

\section{Training procedure}

The violent video game group (5 participants dropped out between pre- and posttest, resulting in a group of $n=25$, mean age $=26.6$ years, $\mathrm{SD}=6.0,14$ females) played the game Grand Theft Auto $V$ on a Playstation 3 console over a period of 8 weeks. The active control group played the non-violent video game Sims 3 on the same console (6 participants dropped out, resulting in a group of $n=24$, mean age $=25.8$ years, $\mathrm{SD}=6.8,12$ females $)$. The 
passive control group ( 2 participants dropped out, resulting in a group of $n=28$, mean age $=30.9$ years, $\mathrm{SD}=8.4,12$ females) was not given a gaming console and had no task but underwent the same testing procedure as the two other groups. The passive control group was not aware of the fact that they were part of a control group to prevent self-training attempts. The experimenters testing the participants were blind to group membership, but we were unable to prevent participants from talking about the game during testing, which in some cases lead to an unblinding of experimental condition. Both training groups were instructed to play the game for at least $30 \mathrm{~min}$ a day. Participants were only reimbursed for the sessions in which they came to the lab. Our previous research suggests that the perceived fun in gaming was positively associated with training outcome [18] and we speculated that enforcing training sessions through payment would impair motivation and thus diminish the potential effect of the intervention. Participants underwent a testing session before (baseline) and after the training period of 2 months (posttest 1) as well as a followup testing sessions 2 months after the training period (posttest 2).

\section{Grand Theft Auto V (GTA)}

GTA is an action-adventure video game situated in a fictional highly violent game world in which players are rewarded for their use of violence as a means to advance in the game. The single-player story follows three criminals and their efforts to commit heists while under pressure from a government agency. The gameplay focuses on an open world (sandbox game) where the player can choose between different behaviours. The game also allows the player to engage in various side activities, such as action-adventure, driving, third-person shooting, occasional role-playing, stealth and racing elements. The open world design lets players freely roam around the fictional world so that gamers could in principle decide not to commit violent acts.

\section{The Sims 3 (Sims)}

Sims is a life simulation game and also classified as a sandbox game because it lacks clearly defined goals. The player creates virtual individuals called "Sims", and customises their appearance, their personalities and places them in a home, directs their moods, satisfies their desires and accompanies them in their daily activities and by becoming part of a social network. It offers opportunities, which the player may choose to pursue or to refuse, similar as GTA but is generally considered as a pro-social and clearly nonviolent game.

\section{Assessment battery}

To assess aggression and associated constructs we used the following questionnaires: Buss-Perry Aggression Questionnaire [19], State Hostility Scale [20], Updated Illinois Rape Myth Acceptance Scale [21, 22], Moral Disengagement Scale [23, 24], the Rosenzweig Picture Frustration Test [25, 26] and a so-called World View Measure [27]. All of these measures have previously been used in research investigating the effects of violent video gameplay, however, the first two most prominently. Additionally, behavioural measures of aggression were used: a Word Completion Task, a Lexical Decision Task [28] and the Delay frustration task [29] (an inter-correlation matrix is depicted in Supplementary Figure 1). From these behavioural measures, the first two were previously used in research on the effects of violent video gameplay. To assess variables that have been related to the construct of impulsivity, we used the Brief Sensation Seeking Scale [30] and the Boredom Propensity Scale [31] as well as tasks assessing risk taking and delay discounting behaviourally, namely the Balloon Analogue Risk Task [32] and a Delay-Discounting Task [33]. To quantify pro-social behaviour, we employed: Interpersonal Reactivity Index [34] (frequently used in research on the effects of violent video gameplay), Balanced Emotional Empathy Scale [35], Reading the Mind in the Eyes test [36], Interpersonal Competence Questionnaire [37] and Richardson Conflict Response Questionnaire [38]. To assess depressivity and anxiety, which has previously been associated with intense video game playing [39], we used Beck Depression Inventory [40] and State Trait Anxiety Inventory [41]. To characterise executive control function, we used a Stop Signal Task [42], a Multi-Source Interference Task [43] and a Task Switching Task [44] which have all been previously used to assess effects of video gameplay. More details on all instruments used can be found in the Supplementary Material.

\section{Data analysis}

On the basis of the research question whether violent video game playing enhances aggression and reduces empathy, the focus of the present analysis was on time by group interactions. We conducted these interaction analyses separately, comparing the violent video game group against the active control group (GTA vs. Sims) and separately against the passive control group (GTA vs. Controls) that did not receive any intervention and separately for the potential changes during the intervention period (baseline vs. posttest 1) and to test for potential long-term changes (baseline vs. posttest 2). We employed classical frequentist statistics running a repeated-measures ANOVA controlling for the covariates sex and age. 


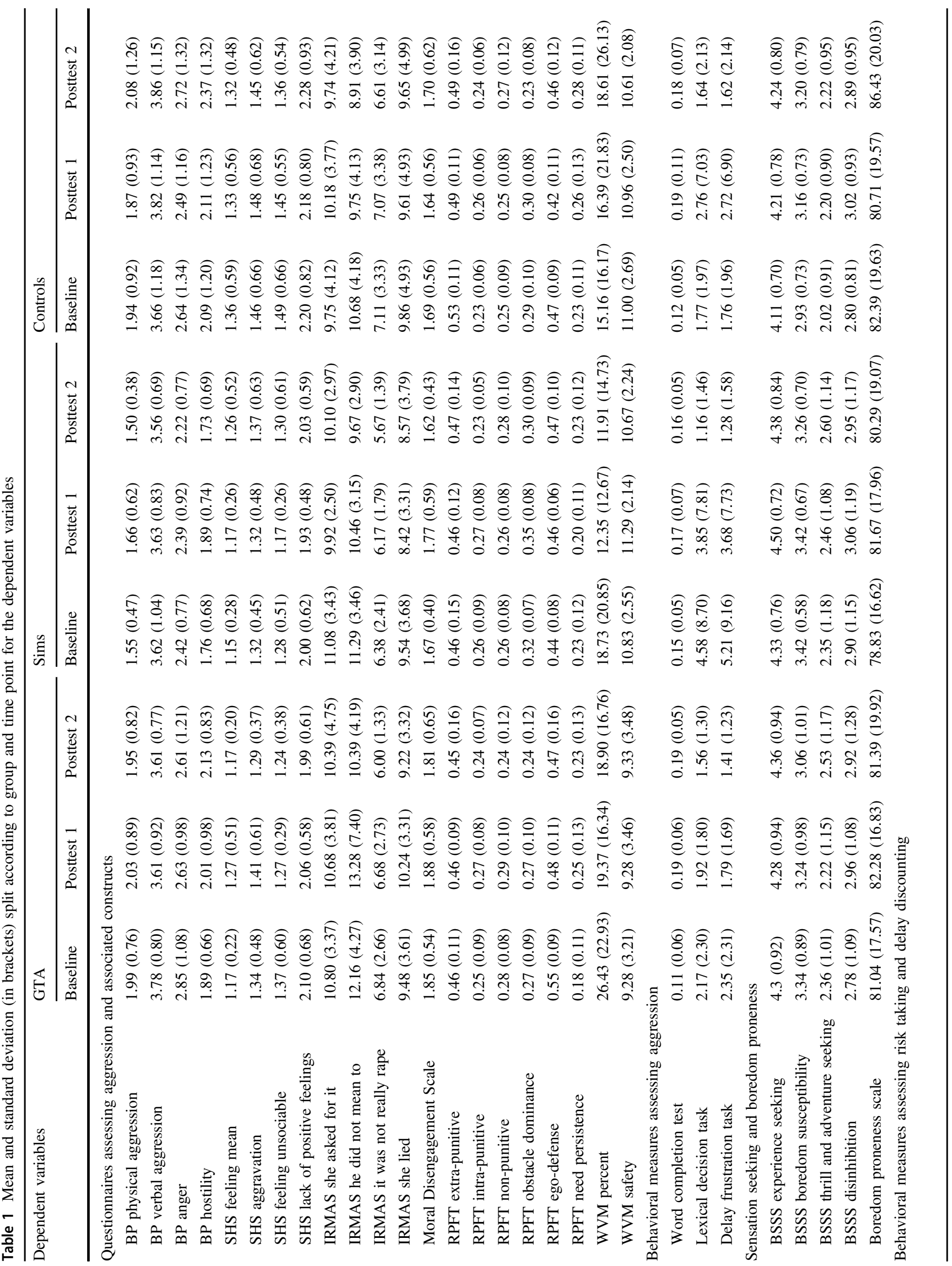




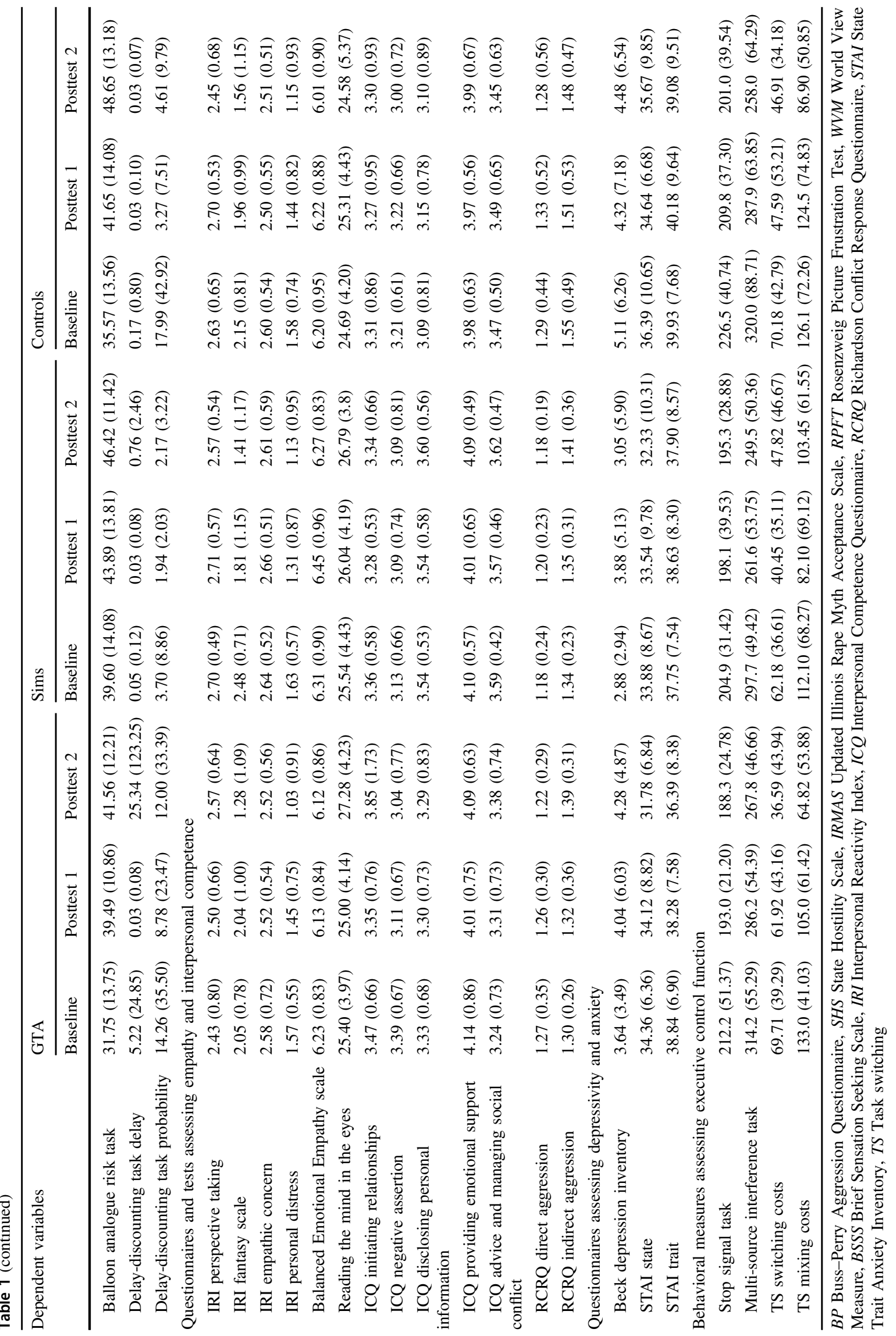




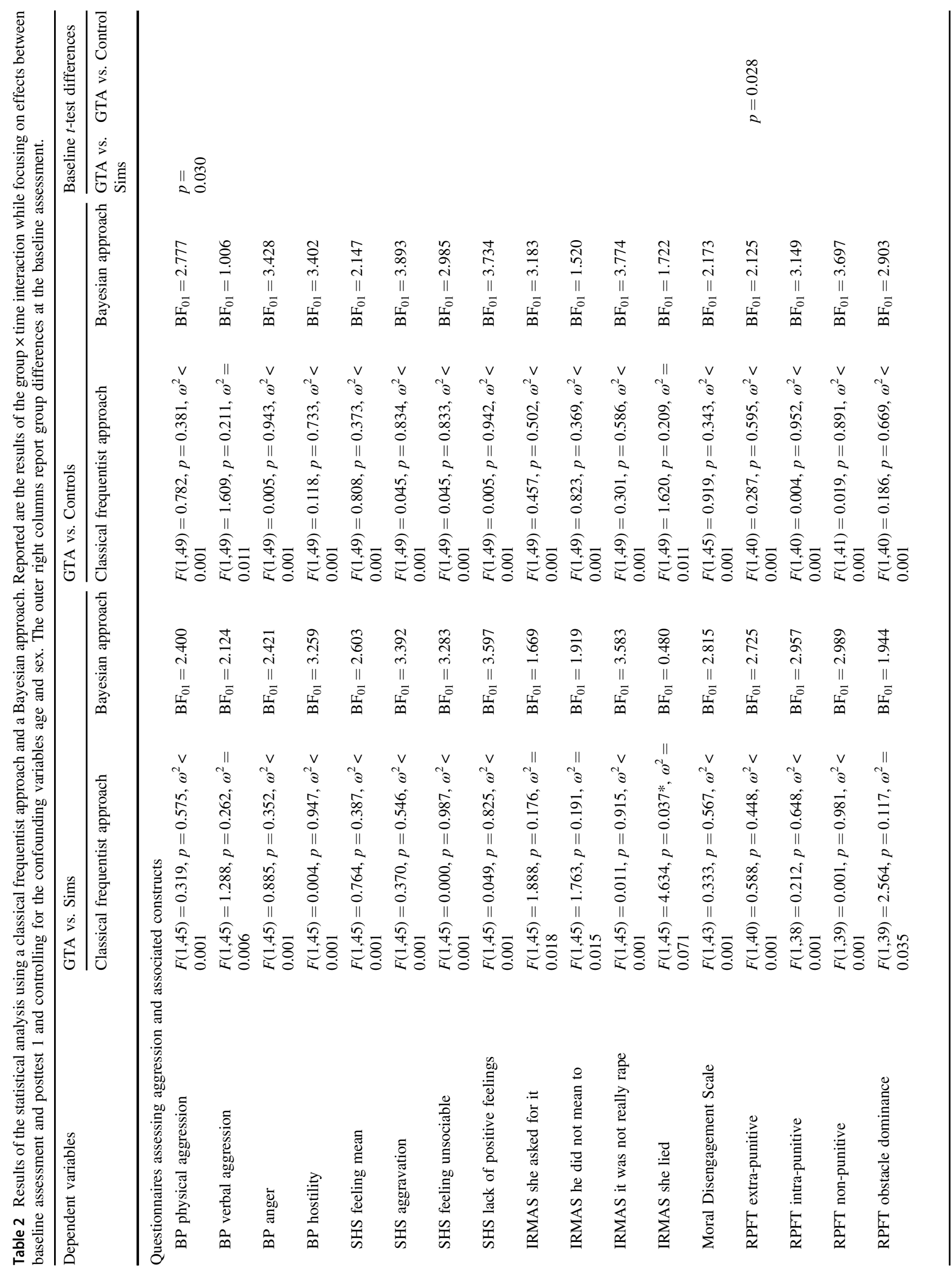




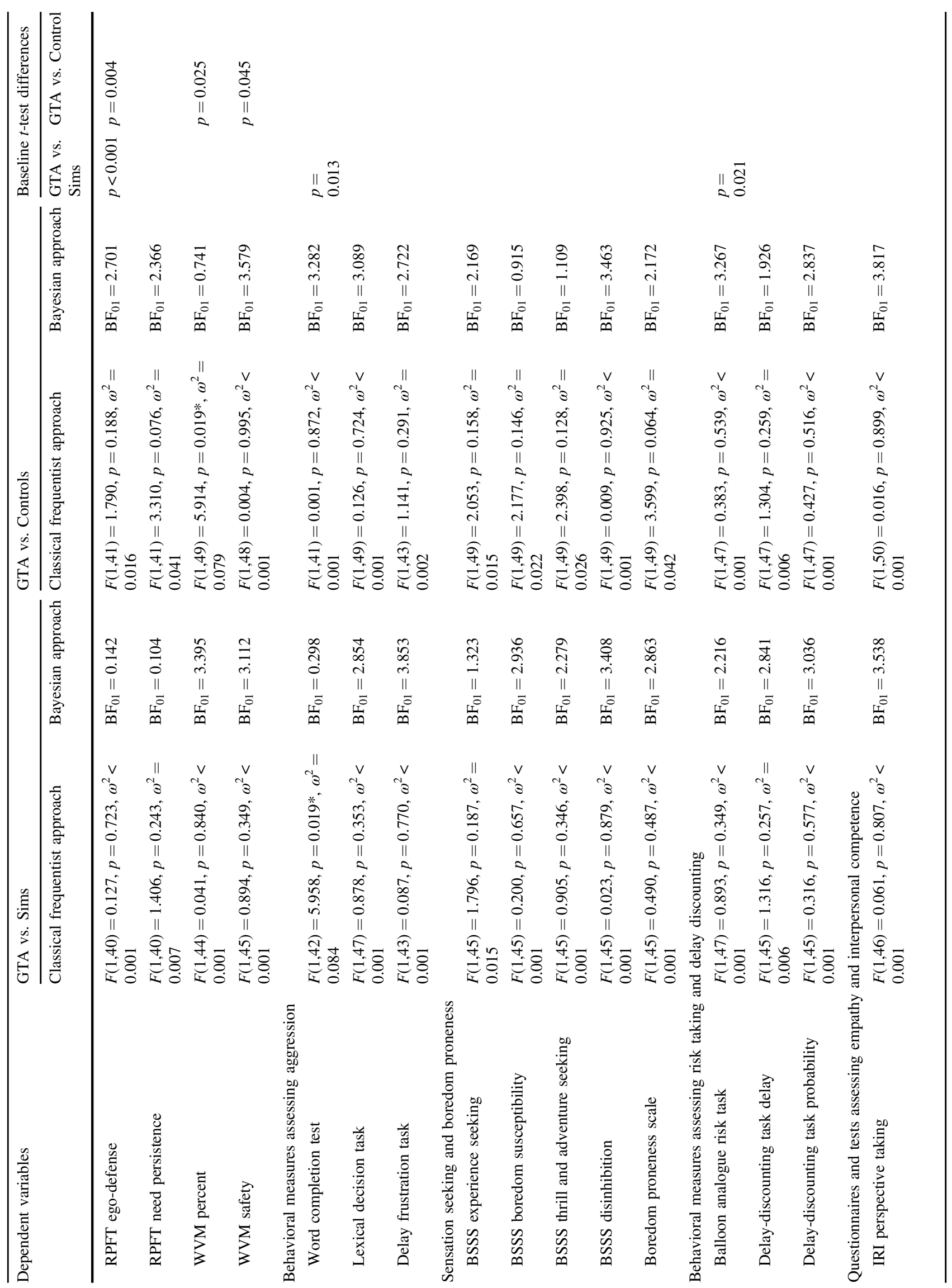




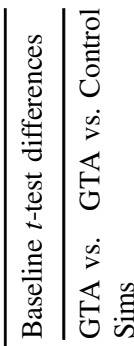

2

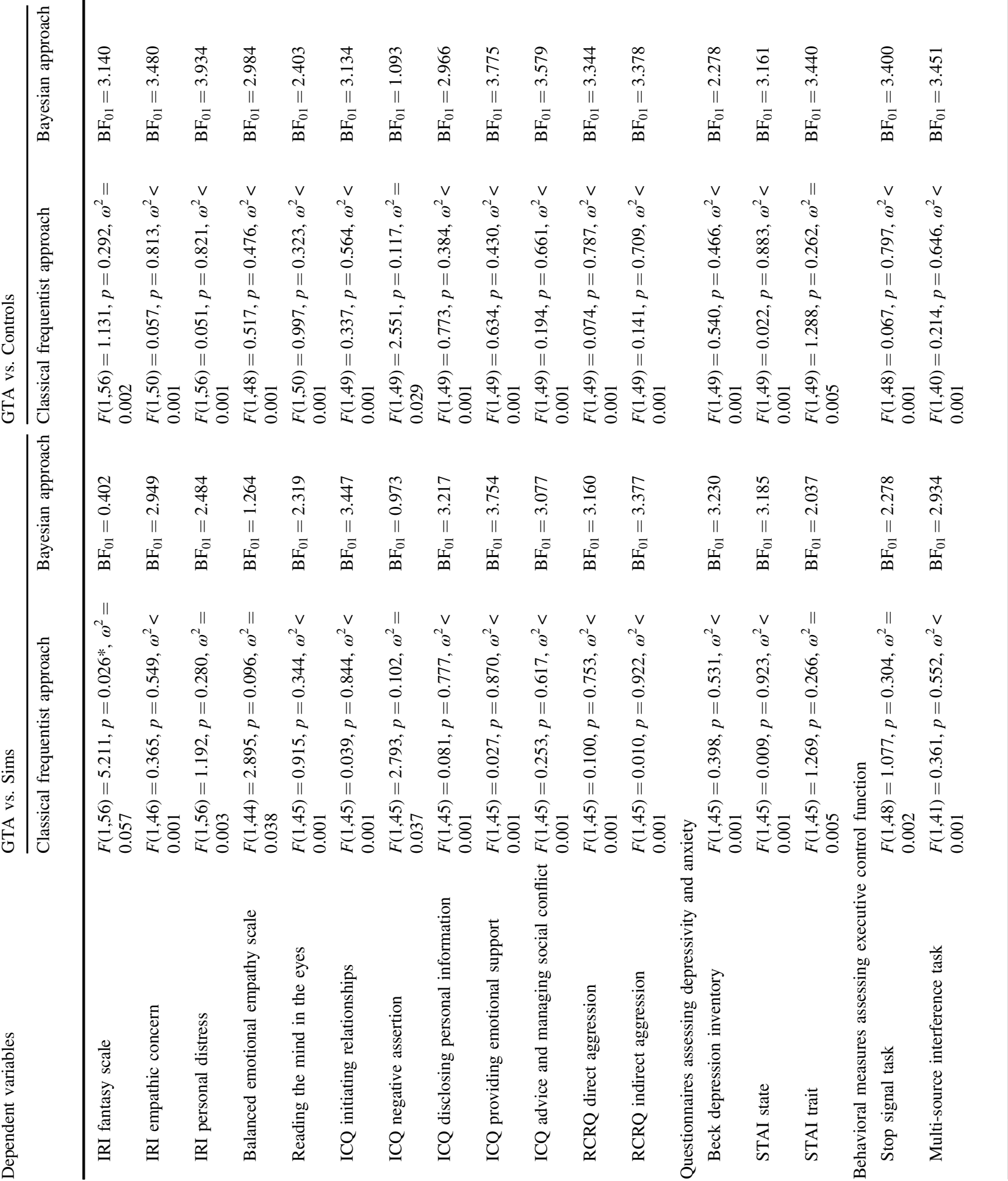




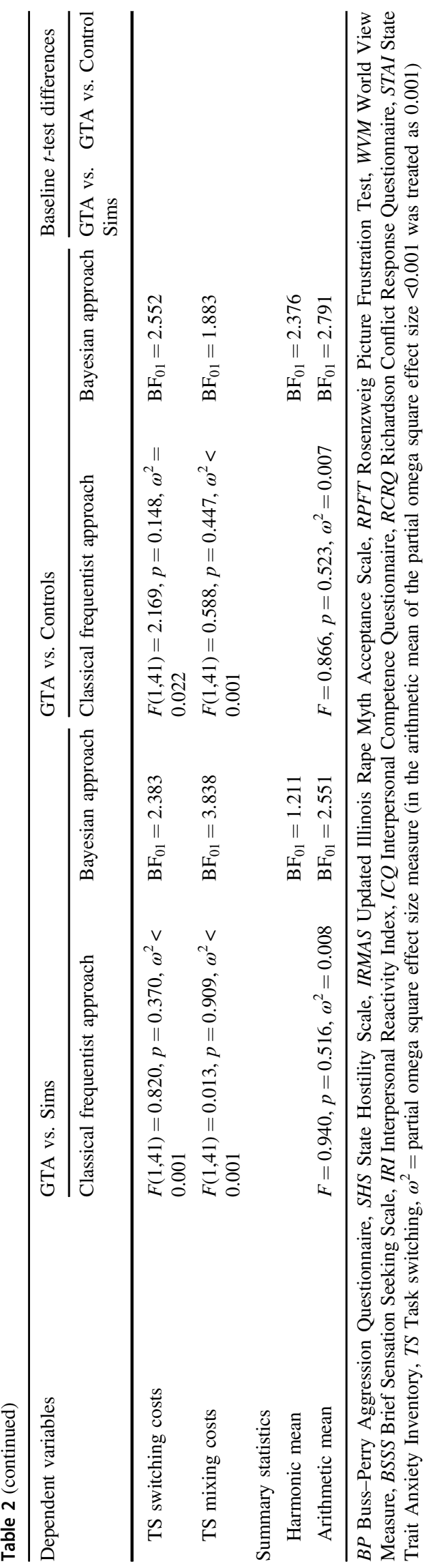

Since we collected 52 separate outcome variables and conduced four different tests with each (GTA vs. Sims, GTA vs. Controls, crossed with baseline vs. posttest 1 , baseline vs. posttest 2 ), we had to conduct $52 \times 4=208$ frequentist statistical tests. Setting the alpha value to 0.05 means that by pure chance about 10.4 analyses should become significant. To account for this multiple testing problem and the associated alpha inflation, we conducted a Bonferroni correction. According to Bonferroni, the critical value for the entire set of $n$ tests is set to an alpha value of 0.05 by taking alpha/ $n=0.00024$.

Since the Bonferroni correction has sometimes been criticised as overly conservative, we conducted false discovery rate (FDR) correction [45]. FDR correction also determines adjusted $p$-values for each test, however, it controls only for the number of false discoveries in those tests that result in a discovery (namely a significant result).

Moreover, we tested for group differences at the baseline assessment using independent $t$-tests, since those may hamper the interpretation of significant interactions between group and time that we were primarily interested in.

Since the frequentist framework does not enable to evaluate whether the observed null effect of the hypothesised interaction is indicative of the absence of a relation between violent video gaming and our dependent variables, the amount of evidence in favour of the null hypothesis has been tested using a Bayesian framework. Within the Bayesian framework both the evidence in favour of the null and the alternative hypothesis are directly computed based on the observed data, giving rise to the possibility of comparing the two. We conducted Bayesian repeatedmeasures ANOVAs comparing the model in favour of the null and the model in favour of the alternative hypothesis resulting in a Bayes factor (BF) using Bayesian Information criteria [46]. The $\mathrm{BF}_{01}$ suggests how much more likely the data is to occur under the null hypothesis. All analyses were performed using the JASP software package (https://jasp-sta ts.org).

\section{Results}

Sex distribution in the present study did not differ across the groups $\left(\chi^{2} p\right.$-value $\left.>0.414\right)$. However, due to the fact that differences between males and females have been observed in terms of aggression and empathy [47], we present analyses controlling for sex. Since our random assignment to the three groups did result in significant age differences between groups, with the passive control group being significantly older than the GTA $(t(51)=-2.10, p=0.041)$ and the Sims group $(t(50)=-2.38, p=0.021)$, we also controlled for age. 


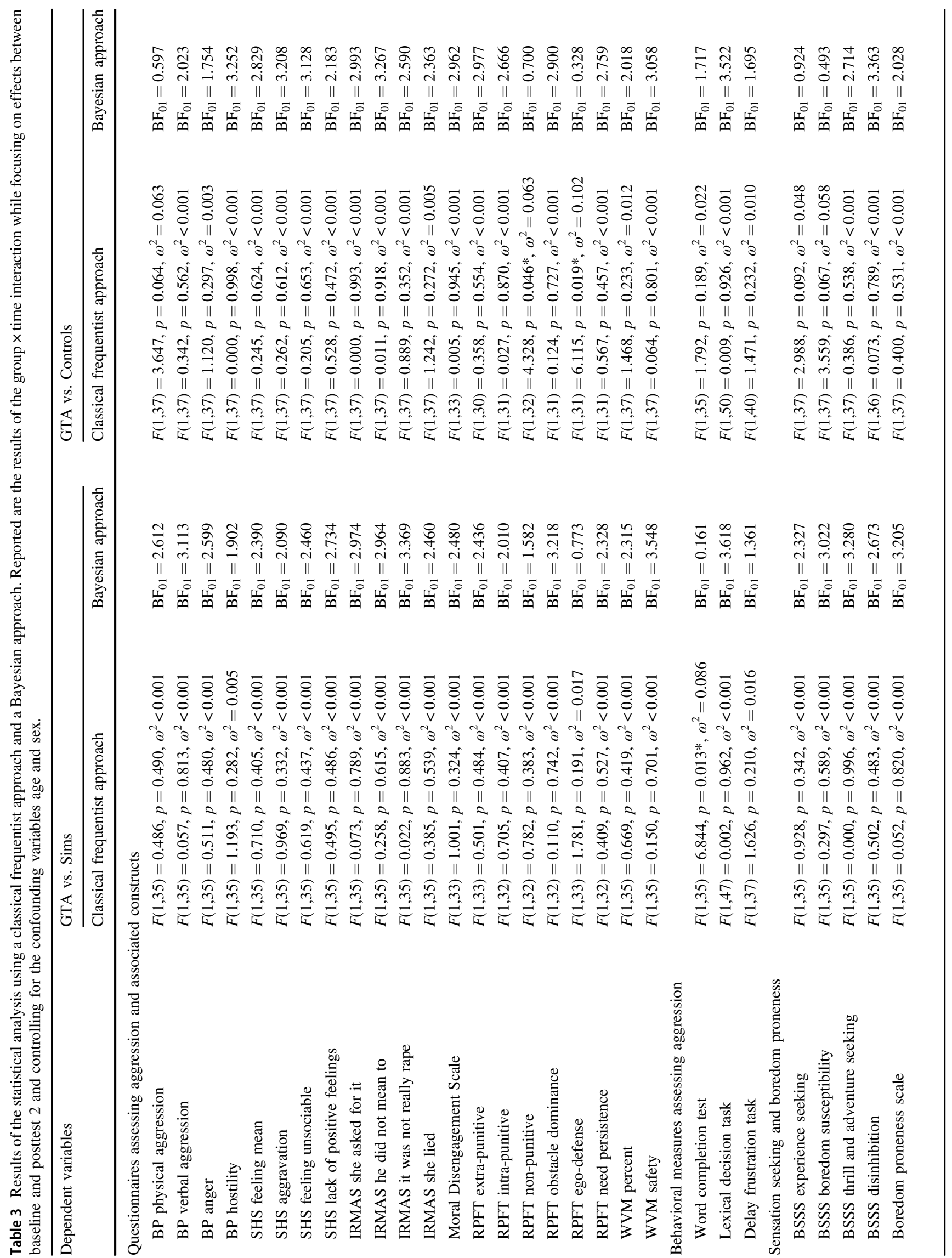




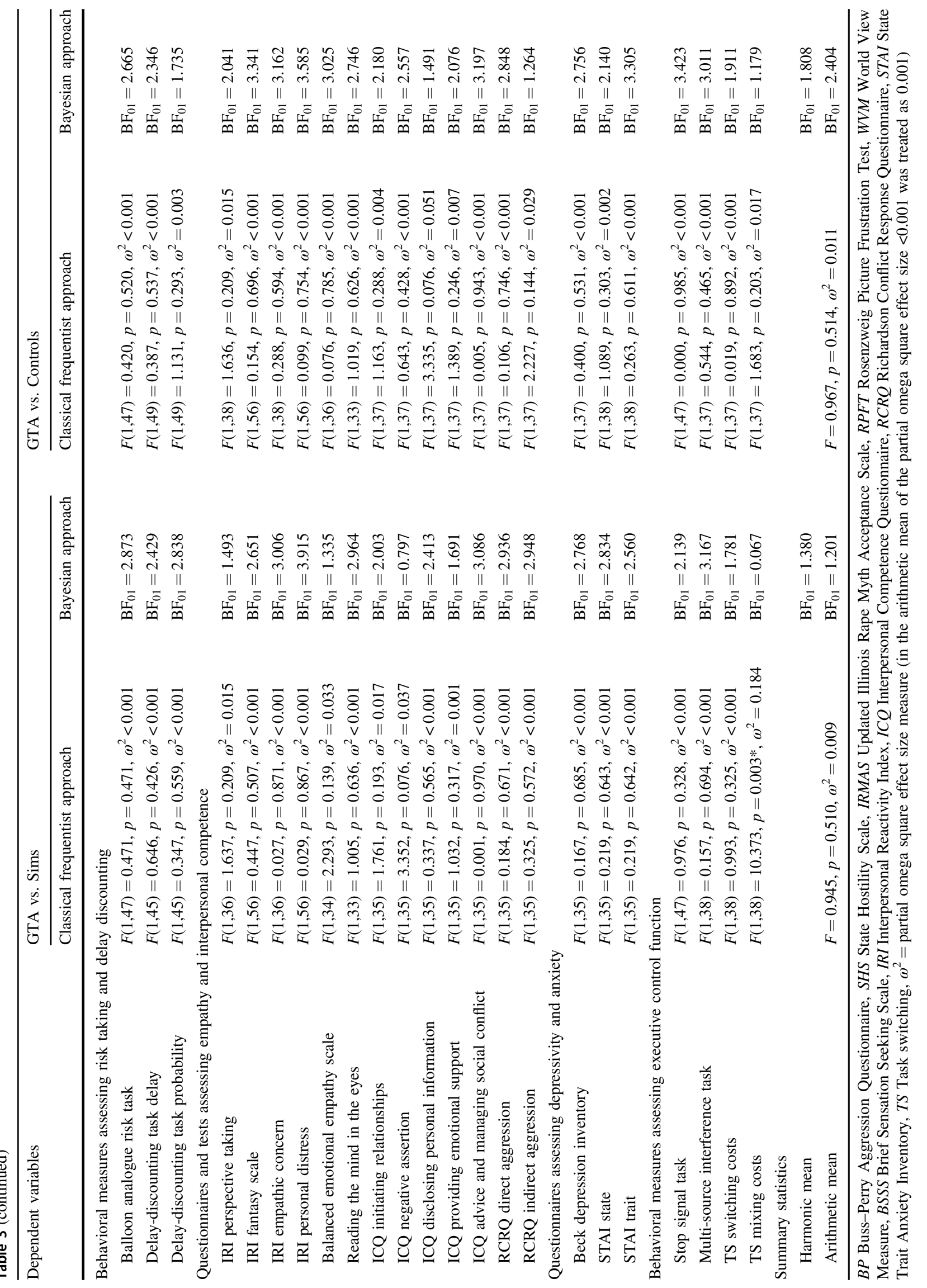


The participants in the violent video game group played on average $35 \mathrm{~h}$ and the non-violent video game group $32 \mathrm{~h}$ spread out across the 8 weeks interval (with no significant group difference $p=0.48$ ).

To test whether participants assigned to the violent GTA game show emotional, cognitive and behavioural changes, we present the results of repeated-measure ANOVA time $\mathrm{x}$ group interaction analyses separately for GTA vs. Sims and GTA vs. Controls (Tables 1-3). Moreover, we split the analyses according to the time domain into effects from baseline assessment to posttest 1 (Table 2) and effects from baseline assessment to posttest 2 (Table 3 ) to capture more long-lasting or evolving effects. In addition to the statistical test values, we report partial omega squared $\left(\omega^{2}\right)$ as an effect size measure. Next to the classical frequentist statistics, we report the results of a Bayesian statistical approach, namely $\mathrm{BF}_{01}$, the likelihood with which the data is to occur under the null hypothesis that there is no significant time $\times$ group interaction. In Table 2, we report the presence of significant group differences at baseline in the right most column.

Since we conducted 208 separate frequentist tests we expected 10.4 significant effects simply by chance when setting the alpha value to 0.05 . In fact we found only eight significant time $\times$ group interactions (these are marked with an asterisk in Tables 2 and 3).

When applying a conservative Bonferroni correction, none of those tests survive the corrected threshold of $p<$ 0.00024. Neither does any test survive the more lenient FDR correction. The arithmetic mean of the frequentist test statistics likewise shows that on average no significant effect was found (bottom rows in Tables 2 and 3).

In line with the findings from a frequentist approach, the harmonic mean of the Bayesian factor $\mathrm{BF}_{01}$ is consistently above one but not very far from one. This likewise suggests that there is very likely no interaction between group $\times$ time and therewith no detrimental effects of the violent video game GTA in the domains tested. The evidence in favour of the null hypothesis based on the Bayes factor is not massive, but clearly above 1 . Some of the harmonic means are above 1.6 and constitute substantial evidence [48]. However, the harmonic mean has been criticised as unstable. Owing to the fact that the sum is dominated by occasional small terms in the likelihood, one may underestimate the actual evidence in favour of the null hypothesis [49].

To test the sensitivity of the present study to detect relevant effects we computed the effect size that we would have been able to detect. The information we used consisted of alpha error probability $=0.05$, power $=0.95$, our sample size, number of groups and of measurement occasions and correlation between the repeated measures at posttest 1 and posttest 2 (average $r=0.68$ ). According to $\mathrm{G}^{*}$ Power [50], we could detect small effect sizes of $f=0.16$ (equals $\eta^{2}=$ 0.025 and $r=0.16$ ) in each separate test. When accounting for the conservative Bonferroni-corrected $p$-value of 0.00024 , still a medium effect size of $f=0.23$ (equals $\eta^{2}=$ 0.05 and $r=0.22$ ) would have been detectable. A metaanalysis by Anderson [2] reported an average effects size of $r=0.18$ for experimental studies testing for aggressive behaviour and another by Greitmeyer [5] reported average effect sizes of $r=0.19,0.25$ and 0.17 for effects of violent games on aggressive behaviour, cognition and affect, all of which should have been detectable at least before multiple test correction.

\section{Discussion}

Within the scope of the present study we tested the potential effects of playing the violent video game GTA $V$ for 2 months against an active control group that played the non-violent, rather pro-social life simulation game The Sims 3 and a passive control group. Participants were tested before and after the long-term intervention and at a followup appointment 2 months later. Although we used a comprehensive test battery consisting of questionnaires and computerised behavioural tests assessing aggression, impulsivity-related constructs, mood, anxiety, empathy, interpersonal competencies and executive control functions, we did not find relevant negative effects in response to violent video game playing. In fact, only three tests of the 208 statistical tests performed showed a significant interaction pattern that would be in line with this hypothesis. Since at least ten significant effects would be expected purely by chance, we conclude that there were no detrimental effects of violent video gameplay.

This finding stands in contrast to some experimental studies, in which short-term effects of violent video game exposure have been investigated and where increases in aggressive thoughts and affect as well as decreases in helping behaviour have been observed [1]. However, these effects of violent video gaming on aggressiveness-if present at all (see above)—seem to be rather short-lived, potentially lasting $<15 \mathrm{~min}[8,51]$. In addition, these shortterm effects of video gaming are far from consistent as multiple studies fail to demonstrate or replicate them [16, 17]. This may in part be due to problems, that are very prominent in this field of research, namely that the outcome measures of aggression and pro-social behaviour, are poorly standardised, do not easily generalise to real-life behaviour and may have lead to selective reporting of the results [3]. We tried to address these concerns by including a large set of outcome measures that were mostly inspired by previous studies demonstrating effects of short-term violent video 
gameplay on aggressive behaviour and thoughts, that we report exhaustively.

Since effects observed only for a few minutes after short sessions of video gaming are not representative of what society at large is actually interested in, namely how habitual violent video gameplay affects behaviour on a more long-term basis, studies employing longer training intervals are highly relevant. Two previous studies have employed longer training intervals. In an online study, participants with a broad age range (14-68 years) have been trained in a violent video game for 4 weeks [52]. In comparison to a passive control group no changes were observed, neither in aggression-related beliefs, nor in aggressive social interactions assessed by means of two questions. In a more recent study, participants played a previous version of GTA for 12 h spread across 3 weeks [53]. Participants were compared to a passive control group using the Buss-Perry aggression questionnaire, a questionnaire assessing impulsive or reactive aggression, attitude towards violence, and empathy. The authors only report a limited increase in pro-violent attitude. Unfortunately, this study only assessed posttest measures, which precludes the assessment of actual changes caused by the game intervention.

The present study goes beyond these studies by showing that 2 months of violent video gameplay does neither lead to any significant negative effects in a broad assessment battery administered directly after the intervention nor at a follow-up assessment 2 months after the intervention. The fact that we assessed multiple domains, not finding an effect in any of them, makes the present study the most comprehensive in the field. Our battery included self-report instruments on aggression (Buss-Perry aggression questionnaire, State Hostility scale, Illinois Rape Myth Acceptance scale, Moral Disengagement scale, World View Measure and Rosenzweig Picture Frustration test) as well as computer-based tests measuring aggressive behaviour such as the delay frustration task and measuring the availability of aggressive words using the word completion test and a lexical decision task. Moreover, we assessed impulserelated concepts such as sensation seeking, boredom proneness and associated behavioural measures such as the computerised Balloon analogue risk task, and delay discounting. Four scales assessing empathy and interpersonal competence scales, including the reading the mind in the eyes test revealed no effects of violent video gameplay. Neither did we find any effects on depressivity (Becks depression inventory) nor anxiety measured as a state as well as a trait. This is an important point, since several studies reported higher rates of depressivity and anxiety in populations of habitual video gamers [54, 55]. Last but not least, our results revealed also no substantial changes in executive control tasks performance, neither in the Stop signal task, the Multi-source interference task or a Task switching task. Previous studies have shown higher performance of habitual action video gamers in executive tasks such as task switching [56-58] and another study suggests that training with action video games improves task performance that relates to executive functions [59], however, these associations were not confirmed by a meta-analysis in the field [60]. The absence of changes in the stop signal task fits well with previous studies that likewise revealed no difference between in habitual action video gamers and controls in terms of action inhibition [61, 62]. Although GTA does not qualify as a classical firstperson shooter as most of the previously tested action video games, it is classified as an action-adventure game and shares multiple features with those action video games previously related to increases in executive function, including the need for hand-eye coordination and fast reaction times.

Taken together, the findings of the present study show that an extensive game intervention over the course of 2 months did not reveal any specific changes in aggression, empathy, interpersonal competencies, impulsivity-related constructs, depressivity, anxiety or executive control functions; neither in comparison to an active control group that played a non-violent video game nor to a passive control group. We observed no effects when comparing a baseline and a post-training assessment, nor when focussing on more long-term effects between baseline and a follow-up interval 2 months after the participants stopped training. To our knowledge, the present study employed the most comprehensive test battery spanning a multitude of domains in which changes due to violent video games may have been expected. Therefore the present results provide strong evidence against the frequently debated negative effects of playing violent video games. This debate has mostly been informed by studies showing shortterm effects of violent video games when tests were administered immediately after a short playtime of a few minutes; effects that may in large be caused by short-lived priming effects that vanish after minutes. The presented results will therefore help to communicate a more realistic scientific perspective of the real-life effects of violent video gaming. However, future research is needed to demonstrate the absence of effects of violent video gameplay in children.

Acknowledgements SK has been funded by a Heisenberg grant from the German Science Foundation (DFG KU 3322/1-1, SFB 936/C7), the European Union (ERC-2016-StG-Self-Control-677804) and a Fellowship from the Jacobs Foundation (JRF 2016-2018).

\section{Compliance with ethical standards}

Conflict of interest The authors declare that they have no conflict of interest. 
Open Access This article is licensed under a Creative Commons Attribution 4.0 International License, which permits use, sharing, adaptation, distribution and reproduction in any medium or format, as long as you give appropriate credit to the original author(s) and the source, provide a link to the Creative Commons license, and indicate if changes were made. The images or other third party material in this article are included in the article's Creative Commons license, unless indicated otherwise in a credit line to the material. If material is not included in the article's Creative Commons license and your intended use is not permitted by statutory regulation or exceeds the permitted use, you will need to obtain permission directly from the copyright holder. To view a copy of this license, visit http://creativecommons. org/licenses/by/4.0/.

\section{References}

1. Anderson CA, Bushman BJ. Effects of violent video games on aggressive behavior, aggressive cognition, aggressive affect, physiological arousal, and prosocial behavior: a meta-analytic review of the scientific literature. Psychol Sci. 2001;12:353-9.

2. Anderson CA, Shibuya A, Ihori N, Swing EL, Bushman BJ, Sakamoto A, et al. Violent video game effects on aggression, empathy, and prosocial behavior in eastern and western countries: a meta-analytic review. Psychol Bull. 2010;136:151-73.

3. Ferguson CJ. Do angry birds make for angry children? A metaanalysis of video game influences on children's and adolescents' aggression, mental health, prosocial behavior, and academic performance. Perspect Psychol Sci. 2015;10:646-66.

4. Ferguson CJ, Kilburn J. Much ado about nothing: the misestimation and overinterpretation of violent video game effects in eastern and western nations: comment on Anderson et al. (2010). Psychol Bull. 2010;136:174-8.

5. Greitemeyer T, Mugge DO. Video games do affect social outcomes: a meta-analytic review of the effects of violent and prosocial video game play. Pers Soc Psychol Bull. 2014;40:578-89.

6. Anderson CA, Carnagey NL, Eubanks J. Exposure to violent media: The effects of songs with violent lyrics on aggressive thoughts and feelings. J Pers Soc Psychol. 2003;84:960-71.

7. DeWall CN, Anderson CA, Bushman BJ. The general aggression model: theoretical extensions to violence. Psychol Violence. 2011;1:245-58.

8. Sestire MA, Bartholow BD. Violent and non-violent video games produce opposing effects on aggressive and prosocial outcomes. J Exp Soc Psychol. 2010;46:934-42.

9. Kneer J, Elson M, Knapp F. Fight fire with rainbows: The effects of displayed violence, difficulty, and performance in digital games on affect, aggression, and physiological arousal. Comput Hum Behav. 2016;54:142-8.

10. Kneer J, Glock S, Beskes S, Bente G. Are digital games perceived as fun or danger? Supporting and suppressing different gamerelated concepts. Cyber Beh Soc N. 2012;15:604-9.

11. Sauer JD, Drummond A, Nova N. Violent video games: the effects of narrative context and reward structure on in-game and postgame aggression. J Exp Psychol Appl. 2015;21:205-14.

12. Ballard M, Visser K, Jocoy K. Social context and video game play: impact on cardiovascular and affective responses. Mass Commun Soc. 2012;15:875-98.

13. Read GL, Ballard M, Emery LJ, Bazzini DG. Examining desensitization using facial electromyography: violent video games, gender, and affective responding. Comput Hum Behav. 2016;62:201-11.

14. Szycik GR, Mohammadi B, Hake M, Kneer J, Samii A, Munte $\mathrm{TF}$, et al. Excessive users of violent video games do not show emotional desensitization: an fMRI study. Brain Imaging Behav. 2017;11:736-43.
15. Szycik GR, Mohammadi B, Munte TF, Te Wildt BT. Lack of evidence that neural empathic responses are blunted in excessive users of violent video games: an fMRI study. Front Psychol. 2017;8:174.

16. Tear MJ, Nielsen M. Failure to demonstrate that playing violent video games diminishes prosocial behavior. PLoS ONE. 2013;8: e68382.

17. Tear MJ, Nielsen M. Video games and prosocial behavior: a study of the effects of non-violent, violent and ultra-violent gameplay. Comput Hum Behav. 2014;41:8-13.

18. Kühn S, Gleich T, Lorenz RC, Lindenberger U, Gallinat J. Playing super Mario induces structural brain plasticity: gray matter changes resulting from training with a commercial video game. Mol Psychiatry. 2014;19:265-71.

19. Buss AH, Perry M. The aggression questionnaire. J Pers Soc Psychol. 1992;63:452.

20. Anderson CA, Deuser WE, DeNeve KM. Hot temperatures, hostile affect, hostile cognition, and arousal: Tests of a general model of affective aggression. Pers Soc Psychol Bull. 1995;21:434-48.

21. Payne DL, Lonsway KA, Fitzgerald LF. Rape myth acceptance: exploration of its structure and its measurement using the illinois rape myth acceptance scale. J Res Pers. 1999;33:27-68.

22. McMahon S, Farmer GL. An updated measure for assessing subtle rape myths. Social Work Res. 2011; 35:71-81.

23. Detert JR, Trevino LK, Sweitzer VL. Moral disengagement in ethical decision making: a study of antecedents and outcomes. J Appl Psychol. 2008;93:374-91.

24. Bandura A, Barbaranelli C, Caprara G, Pastorelli C. Mechanisms of moral disengagement in the exercise of moral agency. J Pers Soc Psychol. 1996;71:364-74.

25. Rosenzweig S. The picture-association method and its application in a study of reactions to frustration. J Pers. 1945;14:23.

26. Hörmann H, Moog W, Der Rosenzweig P-F. Test für Erwachsene deutsche Bearbeitung. Göttingen: Hogrefe; 1957.

27. Anderson CA, Dill KE. Video games and aggressive thoughts, feelings, and behavior in the laboratory and in life. J Pers Soc Psychol. 2000;78:772-90.

28. Przybylski AK, Deci EL, Rigby CS, Ryan RM. Competenceimpeding electronic games and players' aggressive feelings, thoughts, and behaviors. J Pers Soc Psychol. 2014;106:441.

29. Bitsakou P, Antrop I, Wiersema JR, Sonuga-Barke EJ. Probing the limits of delay intolerance: preliminary young adult data from the Delay Frustration Task (DeFT). J Neurosci Methods. 2006;151:38-44.

30. Hoyle RH, Stephenson MT, Palmgreen P, Lorch EP, Donohew RL. Reliability and validity of a brief measure of sensation seeking. Pers Individ Dif. 2002;32:401-14.

31. Farmer R, Sundberg ND. Boredom proneness: the development and correlates of a new scale. J Pers Assess. 1986;50:4-17.

32. Lejuez CW, Read JP, Kahler CW, Richards JB, Ramsey SE, Stuart GL, et al. Evaluation of a behavioral measure of risk taking: the Balloon Analogue Risk Task (BART). J Exp Psychol Appl. 2002;8:75-84.

33. Richards JB, Zhang L, Mitchell SH, de Wit H. Delay or probability discounting in a model of impulsive behavior: effect of alcohol. J Exp Anal Behav. 1999;71:121-43.

34. Davis MH. A multidimensional approach to individual differences in empathy. JSAS Cat Sel Doc Psychol. 1980;10:85.

35. Mehrabian A. Manual for the Balanced Emotional Empathy Scale (BEES). (Available from Albert Mehrabian, 1130 Alta Mesa Road, Monterey, CA, USA 93940); 1996.

36. Baron-Cohen S, Wheelwright S, Hill J, Raste Y, Plumb I. The "Reading the Mind in the Eyes" Test revised version: A study with normal adults, and adults with Asperger syndrome or highfunctioning autism. J Child Psychol Psychiatry. 2001;42:241-51. 
37. Buhrmester D, Furman W, Reis H, Wittenberg MT. Five domains of interpersonal competence in peer relations. J Pers Soc Psychol. 1988;55:991-1008.

38. Richardson DR, Green LR, Lago T. The relationship between perspective-taking and non-aggressive responding in the face of an attack. J Pers. 1998;66:235-56.

39. Maras D, Flament MF, Murray M, Buchholz A, Henderson KA, Obeid N, et al. Screen time is associated with depression and anxiety in Canadian youth. Prev Med. 2015;73:133-8.

40. Hautzinger M, Bailer M, Worall H, Keller F. Beck-DepressionsInventar (BDI). Beck-Depressions-Inventar (BDI): Testhandbuch der deutschen Ausgabe. Bern: Huber; 1995.

41. Spielberger CD, Spielberger CD, Sydeman SJ, Sydeman SJ, Owen AE, Owen AE, et al. Measuring anxiety and anger with the State-Trait Anxiety Inventory (STAI) and the State-Trait Anger Expression Inventory (STAXI). Mahwah, NJ: Lawrence Erlbaum Associates Publishers; 1999.

42. Lorenz RC, Gleich T, Buchert R, Schlagenhauf F, Kuhn S, Gallinat J. Interactions between glutamate, dopamine, and the neuronal signature of response inhibition in the human striatum. Hum Brain Mapp. 2015;36:4031-40.

43. Bush G, Shin LM. The multi-source interference task: an fMRI task that reliably activates the cingulo-frontal-parietal cognitive/ attention network. Nat Protoc. 2006;1:308-13.

44. King JA, Colla M, Brass M, Heuser I, von Cramon D. Inefficient cognitive control in adult ADHD: evidence from trial-by-trial Stroop test and cued task switching performance. Behav Brain Funct. 2007;3:42.

45. Benjamini Y, Hochberg Y. Controlling the false discovery rate: a practical and powerful approach to multiple testing. J R Stat Soc. 1995;57:289-300.

46. Wagenmakers E-J. A practical solution to the pervasive problems of p values. Psychon Bull Rev. 2007;14:779-804.

47. Hay DF. The gradual emergence of sex differences in aggression: alternative hypotheses. Psychol Med. 2007;37:1527-37.

48. Jeffreys H. The Theory of Probability. Oxford: Clarendon Press; 1961.

49. Raftery AE, Newton MA, Satagopan YM, Krivitsky PN. Estimating the integrated likelihood via posterior simulation using the harmonic mean identity. In: Bernardo JM, Bayarri MJ, Berger JO, Dawid AP, Heckerman D, Smith AFM, et al., editors. Bayesian statistics. Oxford: University Press; 2007.
50. Faul F, Erdfelder E, Lang A-G, Buchner A. G*Power3: a flexible statistical power analysis program for the social, behavioral, and biomedical sciences. Behav Res Methods. 2007;39:175-91.

51. Barlett C, Branch O, Rodeheffer C, Harris R. How long do the short-term violent video game effects last? Aggress Behav. 2009;35:225-36.

52. Williams D, Skoric M. Internet fantasy violence: a test of aggression in an online game. Commun Monogr. 2005;72:217-33.

53. Teng SK, Chong GY, Siew AS, Skoric MM. Grand theft auto IV comes to Singapore: effects of repeated exposure to violent video games on aggression. Cyber Behav Soc Netw. 2011;14:597-602.

54. van Rooij AJ, Kuss DJ, Griffiths MD, Shorter GW, Schoenmakers TM, Van, de Mheen D. The (co-)occurrence of problematic video gaming, substance use, and psychosocial problems in adolescents. J Behav Addict. 2014;3:157-65.

55. Brunborg GS, Mentzoni RA, Froyland LR. Is video gaming, or video game addiction, associated with depression, academic achievement, heavy episodic drinking, or conduct problems? J Behav Addict. 2014;3:27-32.

56. Green CS, Sugarman MA, Medford K, Klobusicky E, Bavelier D. The effect of action video game experience on task switching. Comput Hum Behav. 2012;28:984-94.

57. Strobach T, Frensch PA, Schubert T. Video game practice optimizes executive control skills in dual-task and task switching situations. Acta Psychol. 2012;140:13-24.

58. Colzato LS, van Leeuwen PJ, van den Wildenberg WP, Hommel B. DOOM'd to switch: superior cognitive flexibility in players of first person shooter games. Front Psychol. 2010;1:8.

59. Hutchinson CV, Barrett DJK, Nitka A, Raynes K. Action video game training reduces the Simon effect. Psychon B Rev. 2016;23:587-92.

60. Powers KL, Brooks PJ, Aldrich NJ, Palladino MA, Alfieri L. Effects of video-game play on information processing: a metaanalytic investigation. Psychon Bull Rev. 2013;20:1055-79.

61. Colzato LS, van den Wildenberg WP, Zmigrod S, Hommel B. Action video gaming and cognitive control: playing first person shooter games is associated with improvement in working memory but not action inhibition. Psychol Res. 2013;77:234-9.

62. Steenbergen L, Sellaro R, Stock AK, Beste C, Colzato LS. Action video gaming and cognitive control: playing first person shooter games is associated with improved action cascading but not inhibition. PLoS ONE. 2015;10:e144364. 